\title{
PATTERN OF UNINTENTIONAL POISONING BY SUBSTANCES OF ABUSE AMONG CHILDREN UNDER 6 YEARS OLD PRESENTED TO THE POISON CONTROL CENTER OF AIN SHAMS UNIVERSITY HOSPITALS, EGYPT: A RETROSPECTIVE STUDY
}

\author{
Rania Hussien $^{a}$, Mohamed Essam ${ }^{\mathrm{b}}$, Abdallah El Kholy ${ }^{\mathrm{b}}$, Mahmoud Sedki ${ }^{\mathrm{b}}$, Ahmed Abd \\ El Naby ${ }^{\text {b }}$ \\ aDepartment of Forensic Medicine and Clinical Toxicology, Faculty of Medicine, Ain Shams \\ University, ${ }^{\mathbf{b}} 5^{\text {th }}$ Year Students in Armed Forces College of Medicine (AFCM) \\ Corresponding author: Rania Hussien \\ E-mail: raniahussien@med.asu.edu.eg \\ Postal address: Department of Forensic Medicine and Clinical Toxicology, Faculty of \\ Medicine, Ain Shams University, Cairo, Egypt. \\ Telephone: +201006192080
}

Background: Unintentional poisoning by substances of abuse in children is a rare type of acute poisoning but recently, it has been increased in many countries. Low dose of these substances can be fatal for children under 6 years old resulting in severe morbidity and mortality if it is not timely diagnosed and properly managed. Aim: this study aimed to describe the pattern of unintentional poisoning by substances of abuse among children below 6 years old who were presented to the Poison Control Center of Ain Shams University Hospitals (PCC-ASUH), Egypt during a 4 -year period (2014-2017). Material and methods: A retrospective study was performed on all infants and children aged less than 6 years old with unintentional poisoning by substances of abuse presented to the PCC-ASUH during the four years period (2014-2017). The data were collected and included: demographic, poisoning and clinical data. Treatment given to the patients, length of hospital stays as well as outcome of patients were also recorded. Results: During the studied period (2014- 2017), there were 436 children below 6 years old with unintentional poisoning by substances of abuse. Children from 1 to 2 years old were the most vulnerable age group to unintentional poisoning with substances of abuse (64\%), the majority were males (58\%), most of them were from Cairo $(61 \%)$. The most common substance of abuse unintentionally ingested among studied children was cannabis $(64 \%)$, followed by tramadol (33.5\%) and opium $(2.5 \%)$. Loss of consciousness was the most common recorded symptom among children (80\%). Most of the patients were admitted to the inpatient unit $(60 \%)$ while $30 \%$ of cases were admitted to the Intensive Care Unit (ICU). There were 9 deaths (2\%): eight children were intoxicated with tramadol and one child with opium poisoning. Conclusion: This study concluded that unintentional poisoning by substances of abuse in children is a life threatening condition and clinicians should consider it if any child presented to the ER with sudden onset of coma without any history of fever or primary illness. The most frequent unintentionally ingested substance of abuse among children was cannabis followed by tramadol.

Keywords: Poisoning, substance abuse, children, Egypt 


\section{INTRODUCTION}

Substance abuse has been a public health problem worldwide (Calhoun et al., 2015). It affects not only the user, but it also has a negative impact on children by affecting their safety and well-being (Lander et al., 2013). According to reports from the National Survey on Drug Use and Health in the United States, about 8 million children are living with at least one addict parent (U.S., 2009). These children are more likely to be neglected as abusing of these substances affect the concentration and attention of caregivers leading to a poor supervision of their children (DinisOliveira RJ and Magalhães T, 2013; Lander et al., 2013 ).

Unintentional poisoning in children by substances of abuse is a rare type of acute poisoning but it has recently increased in many countries (Ragab et al., 2014) due to several factors as increasing use of illicit substances by family members making it easily available to children at home and the policy of some countries that do not criminalize some of these substances such as tramadol and marijuana (Ragab et al., 2014; Claudet et al., 2017).

Moreover, development of the exploratory behavior in children at this age and also attractiveness and palatability of some of these illicit substances augment the risk for unintentional poisoning among children (Ahmadi et al., 2010). Besides, it could be transmitted through milk to infants by addict mothers causing severe toxicity and even death (Hussien, 2017).

The pattern of unintentional poisoning by substances of abuse among children varies from country to country depending upon the widespread use of the abused substance by adults in each community (Mehrpour et al., 2015). It is important to know the pattern of this type of poisoning in children in order to identify their risk factors for early diagnosis and better management of such cases (Pirzadeh et al., 2016). However, to our knowledge, no study in our community throws light on this type of poisoning in children.
This study was conducted to describe the pattern of unintentional poisoning by substances of abuse among children below 6 years old presented to the Poison Control Center of Ain Shams University Hospitals (PCC-ASUH) during a 4 year period (2014-2017).

\section{MATERIAL AND METHODS}

This retrospective study included all infants and children aged less than 6 years old with unintentional poisoning by substances of abuse presented to the PCCASUH during the four years period from the first of January 2014 to the end of December 2017. PCC-ASUH is the first and largest national inpatient poisoning treatment center in Egypt and the Middle East, it receives nearly about 20.000 poisoning cases annually from Cairo and other Egyptian governorates. It is considered as one of the unique centers at the national scale that is specialized in dealing with both acute and chronic intoxicated patients with different modes of exposure whether, accidental, suicidal or homicidal, in addition to patients intoxicated with substances of abuse (Azab et al., 2016).

The selection of cases was based on the definite history of poisoning with substance of abuse, suggestive clinical manifestations and/or urinary test for the presence of cannabis, tramadol and opium as documented in the medical records of these children during the studied period. The substances of abuse were grouped under 3 categories which were the most common substances in Egypt; tramadol, cannabis and opium. Cases with insufficient information or unclear diagnosis were excluded from the study. Urine screening for tramadol, cannabis and opium was done using immunoassay techniques then was confirmed by highperformance liquid chromatography (HPLC) and gas chromatography-mass spectrometry (GC-MS) for qualitative and quantitative analysis.

The relevant data of the children were collected from the medical records and 
extracted according to a predesigned data entry form. The data collected included: the demographic data (age, sex, residence), poisoning data (type of substance of abuse, route of intake, manner of poisoning whether unintentional ingestion or through lactation in addict mothers, time interval between poisoning and arrival to the hospital), in addition to the clinical data including: symptoms, general examination (vital signs, skin and pupil examination), neurological, cardiovascular system and respiratory system examinations. The treatment given and the length of the hospital stay were also recorded. Children disposition was recorded as: discharge after observation, admission in the inpatient unit or ICU admission.

Vital signs (heart rate, respiratory rate, blood pressure and body temperature) were assessed according to the table of vital signs in children by age in American heart Association 2015 (American heart association, 2015). A patient's level of consciousness was graded according to a modification of the classification of Reed (Reed et al., 1952).

Confidentiality, all the contents of the medical records were maintained and secured. The information was only available to the investigators for the research purpose. Approval of the Ethical Committee of Ain Shams University was taken.

The database created was analyzed using SPSS version 20. Chi square test was used to evaluate the relationship between the variables. Multiple regression analysis was used to estimate the association of selected demographic variables and death. A P-value of less than 0.05 was considered statistically significant.

\section{RESULTS}

This retrospective study involved 436 children below 6 years old with unintentional poisoning by substances of abuse and were admitted to the PCCASUH during the 4 years of the studied period (2014 to 2017). The number of children increased progressively from 89 in 2014 to 96 in 2015, 116 in 2016 and 135 in 2017.Table 1 shows the demographic data of studied children. This study revealed that children from 1 to 2 years old were the most vulnerable age group to unintentional poisoning by substances of abuse $(64 \%)$.

The majority of the studied children were males $(58 \%)$. Most of cases were from Cairo (61\%) followed by Kalioubeya (18\%). The most common substance of abuse among the studied children was cannabis $(64 \%)$, followed by tramadol (33.5\%) and opium (2.5\%). The poisonings were mostly unintentional $(97.5 \%)$, although there were $11(2.5 \%)$ of the cases were exposed through milk by breastfeeding from mothers addicted to tramadol. The only route of poisoning among the cases was through ingestion. About two thirds of the studied children $(67 \%)$ were presented to the PCC-ASUH within 2-6 hours of ingestion.

Table (1): Demographic characteristics of studied children

\begin{tabular}{|l|c|c|}
\hline & Number (436) & Percentage (\%) \\
\hline Age & 39 & $9 \%$ \\
$<1$ year & 279 & $64 \%$ \\
$1-2$ year & 118 & $27 \%$ \\
\hline-5 year & & \\
Sex & 253 & $58 \%$ \\
Male & 183 & $42 \%$ \\
Female & & \\
\hline Residence & 266 & $61 \%$ \\
Cairo & 61 & $14 \%$ \\
Giza & 78 & $18 \%$ \\
Kalioubeya & 9 & $2 \%$ \\
Upper Egypt & 22 & $5 \%$ \\
Others & & \\
\hline
\end{tabular}




\begin{tabular}{|l|c|c|}
\hline Type of poisoning & 279 & $64 \%$ \\
Cannabis & 146 & $33.5 \%$ \\
Tramadol & 11 & $2.5 \%$ \\
Opium & & \\
\hline Mode of poisoning & 425 & $97.5 \%$ \\
Unintentional & 11 & $2.5 \%$ \\
Breastfeeding & 65 & $15 \%$ \\
\hline Delay time & 292 & $67 \%$ \\
$<2$ hours & 79 & $18 \%$ \\
$2-6$ hour & & \\
$>6$ hour & & $14.5 \%$ \\
\hline
\end{tabular}

The most frequent manifestations were neurological; coma was found in $(80 \%)$ of the cases and drowsiness in $20 \%$ followed by gastrointestinal manifestations like vomiting (10\%). Regarding cardiovascular manifestations; tachycardia was found in
$14.5 \%$ of cases, bradycardia in 4 cases $(1 \%)$, hypotension in $2 \%$ and hypertension in 2 cases only $(0.5 \%)$. Respiratory examination revealed bradypnea in $7.5 \%$ and respiratory distress in $3.5 \%$ (Table 2 ).

Table (2): Clinical findings of studied children

\begin{tabular}{|l|c|c|}
\hline & Number (436) & Percentage (\%) \\
\hline Neurological & 349 & \\
Coma & 78 & $80 \%$ \\
Drowsiness & 24 & $20 \%$ \\
Agitation & 24 & $5.5 \%$ \\
Convulsions & & $5.5 \%$ \\
\hline Cardiovascular & 63 & $14.5 \%$ \\
Tachycardia & 4 & $1 \%$ \\
Bradycardia & 9 & $2 \%$ \\
Hypotension & 2 & $0.5 \%$ \\
Hypertension & 44 & $10 \%$ \\
\hline GIT & & \\
Vomiting & 33 & $7.5 \%$ \\
\hline Respiratory & 15 & $3.5 \%$ \\
Bradypnea & & \\
Respiratory distress & & $5 \%$ \\
\hline Others & 22 & $1.5 \%$ \\
Cyanosis & 7 & $19.5 \%$ \\
Fever & 85 & \\
Miosis & 7 & \\
Mydriasis & \multicolumn{2}{|c|}{} \\
\hline
\end{tabular}

Regarding the management required for the studied children, gut decontamination by using gastric lavage was performed in $(14.5 \%)$ of the cases while activated charcoal was administrated in $(19.5 \%)$ and was the most necessary line of treatment among the studied children followed by oxygen therapy (18.5\%) and naloxone as a specific antidote for opium and tramadol $(7.5 \%)$ which was given to the children with respiratory depression. Other medications were administered to patients such as sedative hypnotics to control convulsions and agitation in 24 cases (5.5\%), $\mathrm{H} 2$ blockers in $33(7.5 \%)$ and steroids in 17 cases (4\%).

Most of the patients were admitted to the inpatient unit 262 cases $(60 \%)$ while 150 cases $(34.5 \%)$ were admitted to the Intensive Care Unit (ICU) and only 22 cases $(5 \%)$ were observed for 6 hours in the ER and then discharged. Regarding the duration of hospital stay, most of patients (90\%) were hospitalized between 24-48 hours while 22 cases (5\%) stayed for 6 hours in ER and then discharged and 22 cases $(5 \%)$ were hospitalized for more than 48 hours. The majority of the children 
included in the current study (98\%) improved and were discharged after receiving the appropriate treatment.

Table 3 shows the characteristics of fatalities. Among all (436 children), there were 9 deaths (2\%): eight children were intoxicated with tramadol and one child with opium poisoning. Most of fatalities were males, majority of them were child aged 2-3 years. The most common manner of poisoning was unintentional ingestion. Most of them required endotracheal intubation and mechanical ventilation. Seizures were detected in $33.5 \%$ of cases.

Table (3): Characteristics of fatalities

\begin{tabular}{|c|c|c|c|c|c|c|c|c|}
\hline Case & Age & Gender & $\begin{array}{c}\text { Type of } \\
\text { poisoning }\end{array}$ & $\begin{array}{l}\text { Manner of } \\
\text { poisoning }\end{array}$ & $\begin{array}{l}\text { Delay time } \\
\text { (hr) }\end{array}$ & Presentation & $\begin{array}{c}\text { Endotracheal } \\
\text { intubation }\end{array}$ & Seizures \\
\hline 1 & 2 & Male & Opiate & Unintentional & 6 & $\begin{array}{l}\text { Respiratory } \\
\text { failure }\end{array}$ & Yes & No \\
\hline 2 & 2 & Male & Tramadol & Unintentional & 5 & $\begin{array}{l}\text { Respiratory } \\
\text { failure }\end{array}$ & Yes & No \\
\hline 3 & 3 & Male & Tramadol & Unintentional & 5 & Shock & No & No \\
\hline 4 & 3 & Female & Tramadol & Unintentional & 6 & $\begin{array}{c}\text { Respiratory } \\
\text { failure }\end{array}$ & Yes & Yes \\
\hline 5 & 2 & Male & Tramadol & Unintentional & 6 & $\begin{array}{l}\text { Respiratory } \\
\text { failure }\end{array}$ & Yes & No \\
\hline 6 & 3 & Male & Tramadol & Unintentional & 6 & Shock & No & No \\
\hline 7 & 3 & Male & Tramadol & Unintentional & 5 & $\begin{array}{l}\text { Respiratory } \\
\text { failure }\end{array}$ & Yes & No \\
\hline 8 & $\begin{array}{c}3 \\
\text { months }\end{array}$ & Female & Tramadol & Breastfeeding & 8 & $\begin{array}{c}\text { Respiratory } \\
\text { failure }\end{array}$ & Yes & Yes \\
\hline 9 & $\begin{array}{c}6 \\
\text { months }\end{array}$ & Male & Tramadol & Breastfeeding & 6 & $\begin{array}{l}\text { Respiratory } \\
\text { failure }\end{array}$ & Yes & Yes \\
\hline
\end{tabular}

Table 4 shows multiple regression analysis for the association between death and demographic variables among the studied children. There was a significant association between death and the type of poisoning $(\beta=0.060, \mathrm{p}<0.001)$. Other demographic variables were nonsignificant

Table (4): Multiple Regression analysis for association between death and demographic variables among the studied children

\begin{tabular}{|c|c|c|c|c|c|}
\hline \multirow{2}{*}{ Model } & \multicolumn{2}{|c|}{ Unstandardized Coefficients } & $\begin{array}{c}\text { Standardized } \\
\text { Coefficients }\end{array}$ & Sig. \\
& \multicolumn{2}{|c|}{} & & \\
\cline { 2 - 5 } & B & Std. Error & Beta & & \\
\hline (Constant) & 0.057 & 0.058 & & 0.995 & 0.320 \\
\hline Age & -0.006 & 0.006 & -0.057 & -1.068 & 0.286 \\
\hline Sex & -0.013 & 0.014 & -0.045 & -0.946 & 0.345 \\
\hline Residence & -0.009 & 0.009 & -0.049 & -1.033 & 0.302 \\
\hline Type of poisoning & 0.060 & 0.014 & 0.228 & 4.360 & $<0.001$ \\
\hline Mode of poisoning & -.0073 & 0.046 & -0.080 & -1.572 & 0.117 \\
\hline Delay time & 0.000 & 0.002 & -0.004 & -0.081 & 0.936 \\
\hline
\end{tabular}

$\mathrm{P}>0.05$ non-significant difference. $\mathrm{P}<0.05$ significant difference

\section{DISCUSSION}

Unintentional poisoning with substances of abuse in children is a lifethreatening toxicity resulting in significant morbidity and mortality (Claudet et al.,
2017). According to records from the PCCASUH of Egypt; 89, 96, 116 and 135cases of unintentional poisoning with substances of abuse aged below 6 years were admitted in the years 2014, 2015, 2016 and 2017 
respectively. This crescendo highlights the inflation of this type of toxicity. Most of children in this study had experienced unintentional oral ingestions as the ingested substances were used by another person in their home mostly by one of their parents and even the studied infants were intoxicated through milk from addict mothers.

The highest percentage of unintentional poisoning was noticed among children aged 1-2 years old (64\%) (table 1). This is in agreement with previous studies reported that this age group was at a greater risk of accidental poisoning as they are active and mobile at the stage of development exploring their surroundings (Shabestari et al., 2014; Shirdelpour et al., 2017). On the other hand, Mehrpour et al. (2015) in Iran and Manzar et al. (2010) in Pakistan found a higher frequency of unintentional poisoning among children aged 2-5 years and explained this by inability of children at this age to differentiate between safe and dangerous objects and placing anything in their mouth to explore it. Our study showed a male predominance $(58 \%)$ which is in accordance with Memon et al.(2010) study who reported that boys are more active than girls which increasing their risks of accidental poisoning. Most of our cases were from Cairo (61\%) .The same findings were presented in previous studies in Egypt (Azab et al., 2016; El Masry and Tawfik, 2013). This could be attributed to the proximity of Cairo to the PCC-ASUH causing easy access of its population seeking medical advice (EI Masry and Tawfik, 2013).

The most common unintentional substance of abuse ingested by studied children was cannabis (64\%) (Table1). This could be explained by the hashish form of cannabis that can be mistaken for a chocolate piece by children (Richards et al., 2017). The high number of cannabis intoxication in our study might be due to the high prevalence of cannabis abuse in our country as $77 \%$ of substance users were using cannabis make this substance easily accessible to children for unintentional ingestion (Hamdi et al., 2016).

A previous study in Iran found hashish as the cause of acute poisoning in $17.68 \%$ of studied children aged between 0-4 years and the authors explained this by the proximity of Iran to Afghanistan and Pakistan where these substances were easily available (Khajeh et al., 2012). Moreover, another study was carried out in France (Claudet et al., 2017) reported that $133 \%$ increase in admission rates of pediatric cannabis intoxication between 2004 and 2014 which was mainly explained by the common popularity of cannabis in France especially hashish with a higher tetra hydro cannabinol (THC) concentration. The United States also had a higher rate of pediatric exposures to cannabis but due to another cause as cannabis is commonly used legally as a food product with attractive packaging similar to candy increasing the risk of accidental poisoning in children (MacCoun and Mello, 2015; Wang et al., 2016). Chronic use of cannabis in adults results in cognitive dysfunction and memory impairment (Shrivastava et al., 2011). These side effects could increase the risk of accidental poisoning in children as users may forget to secure it from their children (Richards et al., 2017).

Following cannabis, tramadol was another illicit drug found in $33.5 \%$ of our studied children (table 1). Tramadol is the second common substance of abuse among Egyptians after cannabis (Elhabiby, 2018) because of the common concept of improving the sexual performance (Salem et al., 2008). Although tramadol is a controlled substance in Egypt, users can still get it illegally without a prescription (Fawzi, 2011). Consequently, its extensive availability in homes with its colorful pills raises the risk of unintentional poisoning in young children as it is very attractive to them. Increase number of children intoxicated accidentally with tramadol in 
the current study is similar to a study in Iran found that opioid poisoning was common among children and referred this to increase its use (Sadeghi-Bojd and Khajeh, 2014). On the other hand, a previous study in France (Orliaguet et al., 2015) suggested that tramadol intoxication is rare among children and reported only a few cases of poisoning compared to our study. Another route of accidental exposure of children to tramadol in the present study occurred through milk excretion in 11 breastfed infants aged from 1 to 11 months. The mothers of these infants were tramadol addicts. Several studies reported slower renal elimination of tramadol and its main metabolite (M1) in infants up to one year which is the age of kidney maturation (T'Jollyn et al., 2015; Vandenbossche et al., 2015). Moreover, infants in the current study could be breastfed from mothers who were CYP2D6 ultra-rapid metabolizers that put them at greater risk of toxicity (Yiannakopoulou, 2015). In addition, Hussien (2017) in Egypt reported death of an 8-months-old infant due to tramadol intoxication through breastfeeding. In contrast to our study, Bloor et al. (2012) stated that tramadol is safe in breastfeeding.

The present study found opium intoxication in $11(2.5 \%)$ cases. Unlike our findings, opium was the most common drug responsible for more than half of poisoning cases and $91 \%$ of deaths among drug intoxicated children in a study conducted in Iran (Cheraghali and Taymori, 2006). This could be attributed to the easy availability of opium in this country.

About two thirds of children (67\%) were presented to the hospital within 2-6 hours of ingestion (table 1). This is in accordance with Morbiwala et al. (2017) who reported that most of his patients were presented within 4 hours after exposure. On the other hand, Dayasiri et al. (2018) observed that $69.1 \%$ of his studied children were presented to the ER within 1 hour of poisoning.
The most frequent manifestations among studied children were neurological as coma which was seen in two thirds of studied children $(80 \%)$, drowsiness in about 20\%, agitation (5.5\%) and convulsions in $5.5 \%$ (table 2). This is in agreement with Zaki et al. (2019) who reported that coma was the most common symptom of substance abuse poisoning due to their CNS depressant effects. A previous study (Tanne et al., 2016) suggested that children presented to ER with sudden onset of neurological manifestations such as coma, agitation or convulsions were highly suggestive for accidental poisoning with substance abuse. The other common symptoms and signs in the current study were pinpoint pupils, tachycardia and vomiting, but bradypnea, cyanosis, respiratory distress and hypotension were also observed. These results are in accordance with Zaki et al. (2019) who noticed presence of the previous symptoms in patients with substance abuse overdose. Opioid toxidrome in children secondary to opium and tramadol intoxication is characterized by the classic triad of coma, bradypnea and miosis (Zamani et al., 2010). Tramadol in high concentrations may induce seizures due to its inhibitory effect on $\gamma$-aminobutyric acid (GABA) receptors secondary to its opioid receptor agonistic activity (Rehni et al., 2008).

The majority of children (98\%) improved and were discharged after receiving the appropriate treatment which might be attributed to the fact that more than two thirds $(67 \%)$ of our cases were presented to the emergency department within 2 to 6 hours following poisoning. This result is in agreement with Elhabiby (2018) who explained that by the small amount taken by his studied children as it was an accidental poisoning not suicidal.

In our study, about two thirds of the children $(60 \%)$ were admitted in the inpatient unit while $34.5 \%$ were admitted in ICU due to complications such as coma, seizures, respiratory distress and respiratory failure. 
Nine deaths (2\%) were observed during the 4-year period of the current study. There was a significant association between death and the type of unintentionally ingested substance $(\mathrm{P}=0.001)$ as the majority of deaths ( 8 cases) were due to tramadol intoxication and only one child died following opium poisoning (table 3,4). The high mortality rate among tramadol intoxicated cases in our study is similar to Alazab et al. (2013) study in Iran which reported that prescription opioids have been recently one of the poison-related causes of death in young children, while this result differs from several reports which demonstrated that death due to tramadol overdose among children is rare (De Decker et al., 2008; Ahmadi et al., 2012). Furthermore, the longer delay time observed among dead cases in our study could be the cause of their bad prognosis.

As a retrospective study, there are some limitations as some data such as the amount of ingested substances among the studied children were not available.

\section{CONCLUSIONS}

This study concluded that unintentional poisoning by substances of abuse in children is a life threatening condition as a low dose of these substances could be fatal for children under 6 years old resulting in severe morbidity and mortality if it is not timely diagnosed and properly managed. Clinicians should consider it if any child is presented to the ER with sudden onset of coma without any history of fever or primary illness. The most frequent substance abuse unintentionally ingested by children was cannabis followed by tramadol. Tramadol exposure in infants may occur through milk excretion in breastfed infants by addict mothers. Widespread of substance abuse in our community increases the risk of its unintentional poisoning among children so educating parents about the risks of exposure of their children to these substances is essential for prevention of this type of poisoning.

\section{REFERENCES}

Ahmadi, A.; Pakravan, N. and Ghazizadeh, Z. (2010): Pattern of acute food, drug, and chemical poisoning in Sari City, Northern Iran. Human and Experimental Toxicology 29(9) 731-738.

Ahmadi, H.; Rezaie, M. and Hoseini, J. (2012): Epidemiology analysis of poisonings with tramadol. J Forensic Res.; 3 (6): 151.

Alazab, R.M.; Elmougy, M.T.; Fayad, R.A.; Abdelsalam, H.F. and Mohamed, A.S. (2013): Risk factors of acute poisoning among children: A study at a poisoning unit of a university hospital in Egypt. South East Asia Journal of Public Health, 2(2), 41-47.

American heart association (2015): In: Pediatric advanced life support (PALS) provider manual. Philadelphia: Lippincott Williams and Wilkins.

Azab, S.; Hirshon, J.M.; Hayesd, B.D.; El-Setouhy, M.; Smith, G.S.; Sakr, M.L. et al. (2016): Epidemiology of acute poisoning in children presenting to the poisoning treatment center at Ain Shams University in Cairo, Egypt, 2009-2013. Clin Toxicol (Phila).; 54(1): 20-26.

Bloor, M.; Paech, M.J. and Kaye, R. (2012): Tramadol in pregnancy and lactation. International Journal of Obstetric Anesthesia (2012) 21, 163167.

Calhoun, S.; Conner, E.; Miller, M. and Messina, N. (2015): Improving the outcomes of children affected by parental substance abuse: a review of randomized controlled trials. Subst Abuse Rehabil. ; 6: 15-24.

Cheraghali, F. and Taymori, M. (2006): Epidemiological Study Of Drug Intoxication In Children. Acta Medica Iranica; 44(1):38-40.

Claudet, I.; Mouvier, S.; Labadie, M.; Manin, C.; Michard-Lenoir, A.; Eyer, D. and Dufour, D. (2017). Unintentional cannabis intoxication in toddlers. Pediatrics, 140(3), e20170017. 
Dayasiri, M.B.K.; Jayamanne, S.F. and Jayasinghe, C.Y. (2018): Patterns and Outcome of Acute Poisoning among Children in Rural Sri Lanka.BMC Pediatrics;18: 274.

De Decker, K.; Cordonnier, J.; Jacobs, W.; Coucke, V.; Schepens, P. and Jorens, P.G. (2008): Fatal intoxication due to tramadol alone; case report and review of the literature. Forensic Sci Int., 175(1):79-82.

Dinis-Oliveira, R.J. and Magalhães, T. (2013): Children intoxications: what is abuse and what is not abuse. Trauma Violence Abuse; 14:113-132.

El Masry, M. and Tawfik, H.M. (2013): 2011 Annual Report of the Poison Control Centre of Ain Shams University Hospital, Cairo, Egypt. Ain Shams Journal of Forensic Medicine and Clinical Toxicology; 20: 10-17.

Elhabiby, M. (2018): Non-Medical use of tramadol in Egypt retrived from: https://www.who.int/medicines/news/20 18/8Egypt.pdf?ua=1

Fawzi, M.M. (2011): Some medicolegal aspects concerning tramadol abuse: the new Middle East youth plague 2010. An Egyptian overview. Egyptian J Forensic Sci.; 1:99-102.

Hamdi, E.; Sabry, N.; Sedrak, A.; Khowailed, A.; Loza, N.; Rabie, M. et al. (2016): Sociodemographic indicators for substance use and abuse in Egypt. $\mathbf{J}$ Addiction Prevention; 4(1): 8.

Hussien, R. (2017): Tramadol intoxication in an 8-months-old infant through breastfeeding: A Case Report. J Clin Toxicol., 7(1):1-3.

Khajeh, A.; Narouie, B. and Noori, N.M. (2012): Patterns of Acute Poisoning in Childhood and Relative Factors in Zahedan, Southeast Iran. Shiraz E Medical Journal; 3(13):19-26.

Lander, L.; Howsare, J. and Byrne, M. (2013): The impact of substance use disorders on families and children: from theory to practice. Soc Work Public Health. ; 28(0): 194-205.
MacCoun, R.J. and Mello, M.M. (2015): Half-baked-the retail promotion of marijuana edibles. N. Engl .J. Med.; 372(11):989-991.

Manzar, N.; Saad, SM.; Manzar, B. and Fatima, S.S. (2010): The study of etiological and demographic characteristics of acute household accidental poisoning in children - a consecutive case series study from Pakistan. BMC Pediatrics; 10:28.

Mehrpour, O. Sharifi, M.D. and Ebrahimi, M. (2015): Pattern of acute pediatric poisonings in Birjand city, east of Iran. International Journal of Medical Toxicology and Forensic Medicine. ; 5(4): 192-200.

Memon, Y.; Majeed, R.; Kolachi, H.B.; Querashi, K. and Sheikhet, S. (2010): Clinical spectrum and outcome of accidental poisoning in children. Biomedica.; 26:92-5.

Morbiwala, S.; Parikh, Y.; Hapani, P.; Kalathia, M.; Shah, Z. and Soodhana, D. (2017): Clinical Profile and outcome of Acute Poisoning in Children Less than 12 years of Age. IAIM; 4(1): 1-6.

Orliaguet, G.; Hamza, J.; Couloigner, V.; Denoyelle, F.; Loriot, M.A.; Broly, F. et al. (2015): A case of respiratory depression in a child with ultrarapid CYP2D6 metabolism of tramadol. Pediatrics ; 135: e753-755.

Pirzadeh, Z.; Jamshidi, M. and Mollamohammadi, M. (2016): Acute poisoning in children referred to Qazvin children hospital (2009 to 2012). J Compr Ped.; 7(4):e40099.

Ragab, A.R.; Al-Mazroua, M.K. and Mahmoud, N.F. (2014): Accidental Substance Abuse Poisoning In Children: Experience of the Dammam Poison Control Center. J. Clin. Toxicol.; 4(3): $1-5$.

Reed, C.E.; Ditioos, M.F. and Foote, C.C. (1952): Acute barbiturate intoxication: a study of 300 cases based on a physiologic system of 
classification of the severity of intoxication. Ann Intern Med; 37: 290

Rehni, A.K.; Singh, I. and Kumar, M. (2008): Tramadol-induced seizurogenic effect: a possible role of opioiddependent gamma-aminobutyric acid inhibitory pathway. Basic Clin Pharmacol Toxicol.; 103(3): 262-266.

Richards, J.R.; Smith, N.E. and Moulin, A.K. (2017): Unintentional cannabis ingestion in children: a systematic review. The Journal of Pediatrics; 190:142-52.

Sadeghi-Bojd, S. and Khajeh, A. (2014): chronological variations of children poisoning causes in Zahedan, south of Iran. Int J High Risk Behav Addict.; 3(3): 1-5.

Salem, E.A.; Delk, J.R.; Wilson, S.K.; Delk, J.R.; Hellstrom, W.J. and Cleves, M.A. (2008): Tramadol HCL has promise in on demand use to treat premature ejaculation. J Sex Med.; 5:188-193.

Shabestari, A.; Purfarzad, A. and Ghorbani, M. (2014): Acute poisoning in children: a hospital-based study in Arak, Iran, 2008-2012. Iranian Journal of Toxicology; 8(26):1104-1108.

Shirdelpour, K.; Shafipour, S.Z.; Mirzaei, M.; Kazem, E.; Leili, N. and Nath, A. (2017): Poisoning and its related factors in children under 6 years old in Rasht. Journal of Holistic Nursing and Midwifery, 27(2), 85-92.

Shrivastava, A.; Johnston, M. and Tsuang, M. (2011): Cannabis use and cognitive dysfunction .Indian J Psychiatry. 2011 Jul-Sep; 53(3): 187191.

T'Jollyn, H.; Snoeys, J.; Vermeulen, A.; Michelet, R.; Cuyckens, F.; Mannens, G.; et al. (2015): Physiologically based pharmacokinetic predictions of tramadol exposure throughout pediatric life: an analysis of the different clearance contributors with emphasis on CYP2D6 maturation. AAPS J. ;17: 1376-1387.

Tanne, C.; Javouhey, E.; Millet, A. Bordet, F. (2016): Severe tramadol overdoses in children: a Case series admitted to paediatric intensive care unit. Journal of Clinical Toxicology, 6(5): 1-5.

U.S. Department of Health and Human Services, SAMHSA, OAS. (2009).

Vandenbossche, J.; Richards, H.; Soli, B. and Van Peer, A. (2015): Singleand multiple-dose pharmacokinetic studies of tramadol immediate-release tablets in children and adolescents. Clin. Pharmacol. Drug Dev. ; 4: 184-192.

Wang, G.S.; Le Lait, M.C.; Deakyne, S.J.; Bronstein, A.C.; Bajaj, L. and Roosevelt, G. (2016): Unintentional pediatric exposures to marijuana in Colorado, 2009-2015.JAMA Pediatr.; 170(9):e160971.

Yiannakopoulou, E. (2015): Pharmacogenomics and opioid analgesics: clinical implications. International Journal of Genomics; vol. 2015, Article ID 368979,

8

pages. https://doi.org/10.1155/2015/368 979

Zaki, A.R.; Ghaleb, S.S.; Abdelmenem, A. and Yousef, M.A. (2019): Retrospective study of addictive drug induced acute toxicity of cases admitted to the Poison Control Centre of Ain Shams University Hospital (20152016). Egyptian Journal of Forensic Sciences; 9:13.

Zamani, N.; Sanaei-Zadeh, H. and Mostafazadeh, B. (2010): Hallmarks of opium poisoning in infants and toddlers. Trop Doct.; 40: 220-2. 
نمط التسم غير المقصود بالمواد المسىع استعمالها بين الأطفال أقل من 6 سنوات الذين حضروا إلى

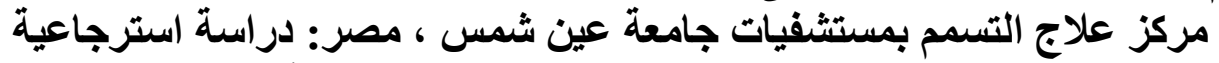

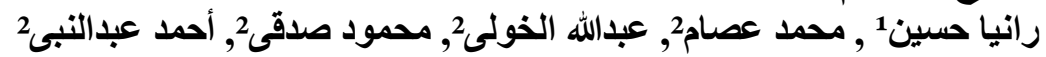

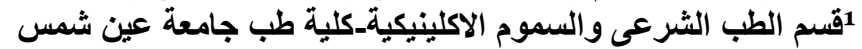

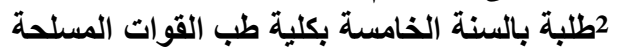

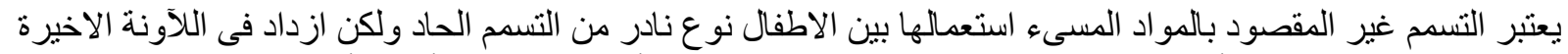

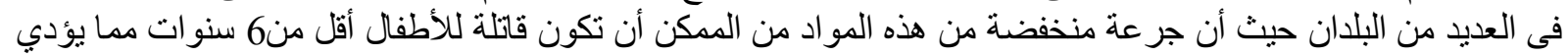

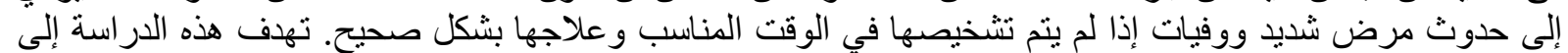

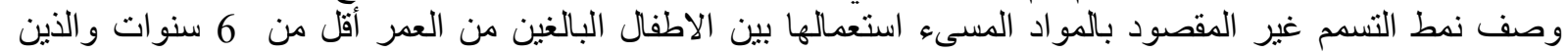

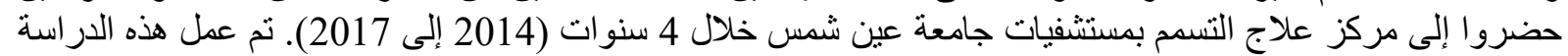

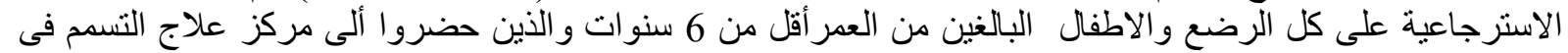

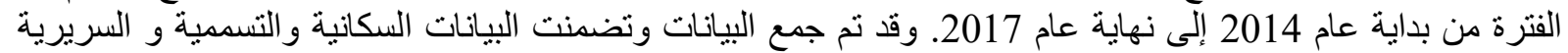

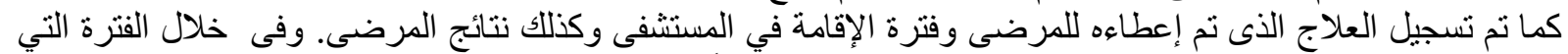

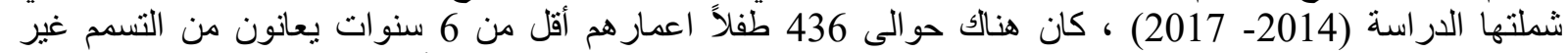

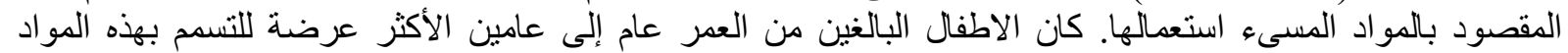

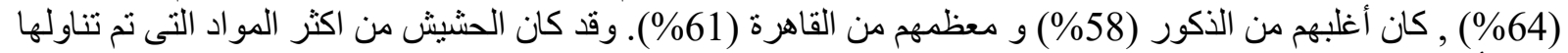

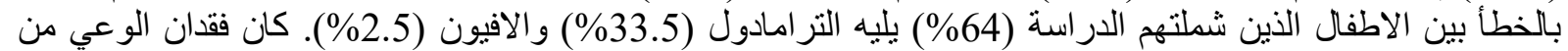

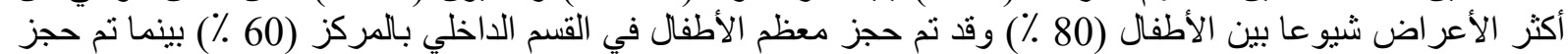

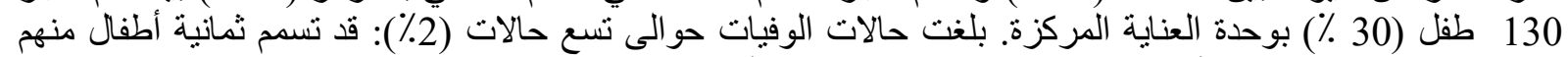

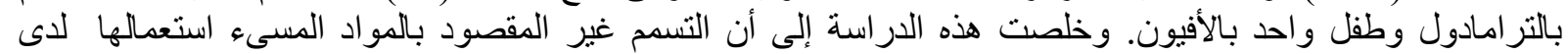

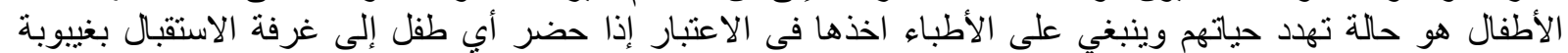

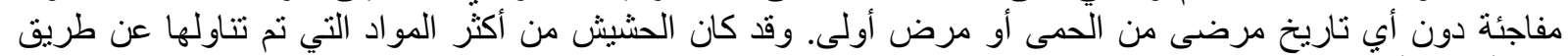
الخطأبين الأطفال (64\%) يليه الترامادول (33.5٪) . 